\title{
Hypoglycaemia in infancy and childhood
}

\author{
GERALD NELIGAN
}

Newcastle

The risk of exposure to the harmful effects of spontaneous hypoglycaemia is greater in the first few years than in the whole of the rest of life. During the acute nutritional crisis which follows birth, blood glucose levels below the accepted lower limit of normal for adults are the rule rather than the exception, particularly in certain predisposed types of baby. Some of these babies show overt symptoms of a neurological disturbance, while others may remain well to all appearances in spite of a persistently low blood glucose level, at least for many hours or days. There is understandable worry that irreversible damage to the brain may occur even in the absence of overt acute symptoms, when it is remembered that organs and cells are most vulnerable at times when they are growing most rapidly. In the case of the human brain, the work of Winick (1968) has added a new precision to the understanding of its growth. He has shown that although there is a linear increase in the weight of the whole brain and of its protein and RNA fractions from the middle third of intrauterine life until at least a year after birth, the weight of the DNA fraction increases in a linear fashion only up to the time of birth at full term, and thereafter increases more slowly for another four or five months only, after which there is no further increase. It appears, therefore, that the most critical phase of new cell formation is completed during the last half of the normal stay in the uterus (much of which is spent by some babies in the potentially more precarious environment of a special care nursery), but that new cells continue to be formed for some months after birth at full term.

The histological damage to the neurones of the brain and spinal cord which can be produced by hypoglycaemia at this age has been demonstrated by Anderson, Milner, and Strich (1967). In three babies who had not been adequately treated there were gross abnormalities, and changes were also detectable even in three who had been adequately treated but who died later from other causes.

Clinical evidence of permanent neurological sequelae is also distressingly frequent, and is commoner the younger the child at the onset of the recognized attacks of hypoglycaemia; Haworth and Coodin (1960) reported an incidence of $51 \%$ with onset under the age of 6 months and $12 \%$ with onset over that age. Ingram, Stark, and Blackburn (1967) found such evidence more frequently in cases of spontaneous hypoglycaemia than in children whose attacks were caused by insulin overdosage, and suggest that this may have been due to the relatively younger age at onset, to the relatively greater delay in making the diagnosis leading to effective treatment, or possibly to underlying abnormalities of the brain which caused both the hypoglycaemia and the neurological signs.

The other special feature of hypoglycaemia in childhood is that there are many causes, or clinical categories, to be seriously considered. Earlier contributions to this symposium have already covered the most important of the inherited disorders of carbohydrate metabolism which may present with, or cause death from, hypoglycaemia soon after birth (glycogenoses, galactosaemia, and fructosaemia). At the same time, those causes of hypoglycaemia which are most important in the adult cannot be entirely ignored. Islet-cell adenoma, rare under the age of 4 years but described in the newborn, has an age incidence characteristic of the lower tail of a distribution centred in adult life. The same probably applies to the hypoglycaemia which may be the presenting symptom in cases of diabetes mellitus, and has been described in childhood by Lloyd (1964).

The great majority of the cases of hypoglycaemia in childhood can as yet only be allocated to one of two broad groups which are defined by the age at onset, ie, neonatal (during first month of life) and infantile (after first month). Certain provisional categories can be identified within each group, defined by clinical or biochemical criteria. The provisional nature of some of these divisions is indicated by the names used, implying uncertainty about the underlying cause, by the fact that the same child may pass from one to the other, as from the neonatal to the infantile group (Neligan, 1965), and by the fact that new divisions are being created 
as new causes or biochemical mechanisms are recognized, such as leucine sensitivity (Cochrane, Payne, Simpkiss, and Woolf, 1956).

\section{NEONATAL HYPOGLYCAEMIA}

During the first few days of life there needs to be a different working definition of the normal lower limit of the blood glucose level, as of so many other values. The limit currently suggested by Cornblath and Schwartz (1966), and widely accepted, is 20 $\mathrm{mg} / 100 \mathrm{ml}$ for babies of low birth weight $(2.5 \mathrm{~kg}$ or below) and up to $30 \mathrm{mg} / 100 \mathrm{ml}$ for bigger babies during the first 72 hours of life, and $40 \mathrm{mg} / 100 \mathrm{ml}$ thereafter. The reason is that symptomatic hypoglycaemia, defined as suggestive neurological signs which can promptly be relieved by 1 to $2 \mathrm{~g}$ of glucose rapidly given intravenously, is not seen in babies of this age whose blood glucose is above these levels. The accepted signs are convulsions, attacks of apnoea with cyanosis, limb tremors ('jitteriness'), and a depressed Moro response.

There are two main aetiological categories of neonatal hypoglycaemia, probably mutually exclusive, and a number of important aggravating factors which may coexist with or complicate either of the main categories, or cause trouble in otherwise unaffected babies.

CATEGORY A: BABIES OF DIABETIC MOTHERS It has long been recognized that these babies tend to have very low blood glucose levels following birth, characteristically within the first few hours. Their islet cells are known to be histologically hypertrophied and able to produce very high blood insulin levels. The idea that this hypertrophy is due to repeated exposure to abnormally high concentrations of glucose before birth is supported by the confirmed observation (Fig. 1) that the behaviour of the babies of non-insulin-treated diabetics falls somewhere between those of insulin-treated diabetics and those of normal mothers (Isles, Dickson, and Farquhar, 1968). Hyperinsulinism could also explain their marked tendency to obesity at birth.

There is disagreement about the clinical implications of this low blood glucose level. Farquhar (1965) stated that 'it is commonly asymptomatic' and did not recommend routine blood glucose measurements; but he did suggest that glucagon should be administered if 'suggestive physical signs' were accompanied by a blood glucose level below $30 \mathrm{mg} / 100 \mathrm{ml}$ beyond the age of 8 hours. However, McCann, Adam, Likly, and Schwartz (1966), who used very sensitive clinical criteria including a raised respiratory rate, showed a correlation between

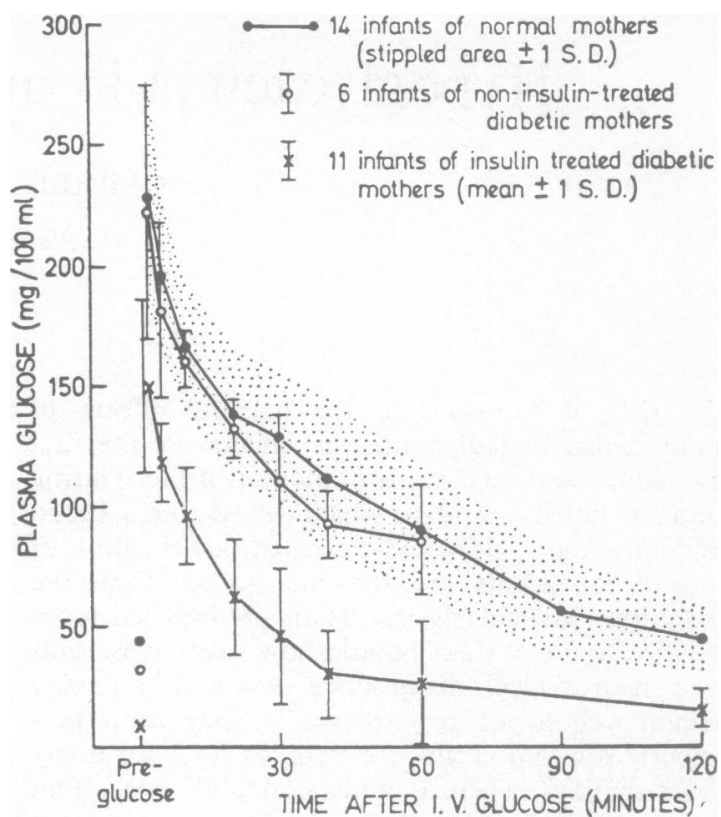

FIG. 1. Mean plasma glucose levels following intravenous glucose $(0.5 \mathrm{~g} / \mathrm{kg}$ body weight $)$ injected at $120 \mathrm{~min}$ utes of life. (After Fig. 1, by Isles, Dickson, and Farquhar, 1968.)

symptoms and low blood glucose levels. They suggested that, until more is known about the longterm neurological prognosis, the hypoglycaemia ought to be prevented by intravenous administration of fructose to the mother in labour, and of fructose or glucose to the baby after birth.

CATEGORY B: BABIES SUFFERING FROM INTRAUTERINE MALNUTRITION These babies are recognizable at birth as being of low birth weight for their gestational age ('light for dates') or as showing obvious signs of wasting. Their blood sugar levels drop significantly below those of well nourished babies by the time of their first feed (Neligan, Robson, and Watson, 1963) and this tendency to hypoglycaemia persists throughout at least the first week of life (Haworth, Dilling, and Younoszai, 1967). As a rule symptoms only develop during the second day of life, probably after many hours of hypoglycaemia. The associated clinical features of 56 cases are summarized by Cornblath and Schwartz (1966); they include an excess of pregnancies complicated by preeclamptic toxaemia, of male babies, of smaller twins, and of babies requiring resuscitation following delivery. The incidence of symptomatic 
cases is estimated at between 1.7 and 2.9 per thousand births (Cornblath and Schwartz, 1966).

The tendency to hypoglycaemia may be explained by the relatively inadequate store of liver glycogen available to sustain them through the usual period of postnatal starvation. The total weight of the liver is reduced relative to that of the brain (Dawkins, 1964), and the concentration of carbohydrate in each unit of liver tissue is also markedly reduced as compared with that in well nourished babies (Shelley and Neligan, 1966). This explanation is supported by the finding that in a symptomatic case the blood sugar level may show no response to adrenalin or glucagon before treatment with glucose (Fig. 2) and that this response can be much improved in asymptomatic babies by pretreatment with glucose during the first 24 hours of life (Rabor, Oh, Wu, Metcoff, Vaughan, and Gabler, 1968). Most other regulatory mechanisms which have been deliberately tested during the neonatal period have been found in working order (Cornblath, Wybregt, and Baens, 1963); but Stern, Sourkes, and Raiha (1967) have shown that recovered cases of spontaneous symptomatic hypoglycaemia may be unable to respond to induced hypoglycaemia with a normal increase in adrenalin output. It is not yet clear whether this is a cause or an effect of their trouble. More recently still it has been reported that hypoglycaemic light-fordates babies may maintain an inappropriately high blood level of immunoreactive insulin (Schiff and Lowy, 1968). One or more of these factors may explain the characteristic, possibly even diagnostic, difficulty of maintaining a normal blood sugar level in symptomatic light-for-dates babies as compared with those whose hypoglycaemia is associated with other factors, such as cerebral haemorrhage (Neligan, 1964).

Since follow-up studies of symptomatic babies have usually shown an incidence of signs of brain damage around $50 \%$, which is higher than in other babies of comparable birth weight (Cox and Dunn, 1967), there is general agreement that routine steps should be taken to make the diagnosis as quickly as possible, and to follow it with the most effective treatment available. Continuous intravenous infusion of $10 \%$ glucose solution, 100 to $110 \mathrm{ml} / \mathrm{kg} / 24$ hours, following the initial test dose of 1 to $2 \mathrm{~g}$, is appropriate in theory and effective in practice. Treatment can usually be stopped after two or three days if the baby is feeding well, but it is wise to follow the blood sugar level for a while thereafter in view of the risk of the hypoglycaemia recurring (as happened in the case illustrated in Fig. 2 where this precaution was omitted). Oral treatment with glucose alone is not

BABY W. BIRTH WEIGHT 2,070 gm AT 39 WEEKS

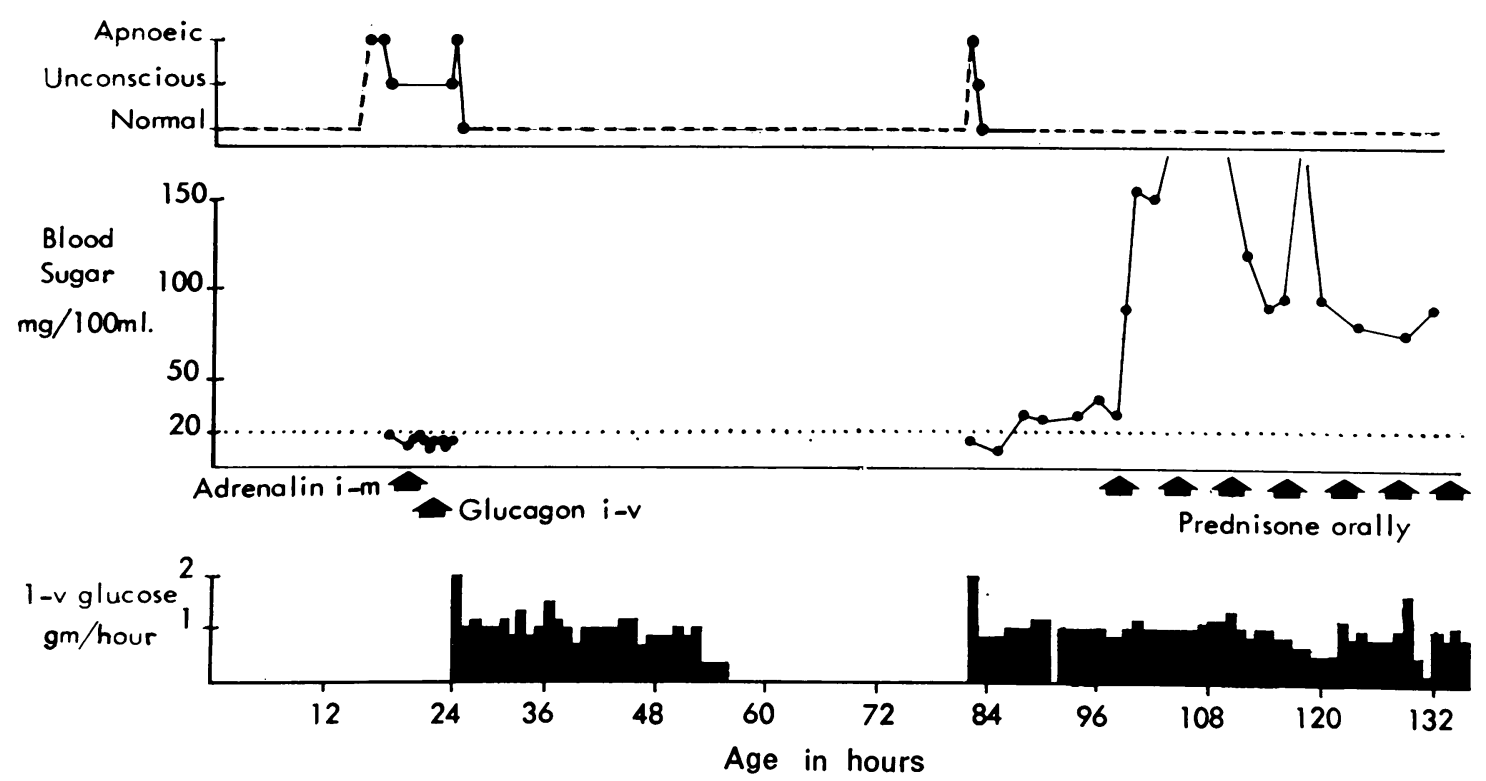

FIG. 2. Variations in blood glucose concentration in a baby of low birth weight $(2,070 \mathrm{~g}$ at 39 weeks). (After figure by Neligan, 1965.) 
effective in such cases, but may possibly become so if accompanied by adrenal glucocorticoids (Creery, 1963).

Even in asymptomatic babies the wisest course at present would seem to be to correct the hypoglycaemia if it persists more than a few hours, since no adequate long-term follow-up studies have as yet been published and we still do not know by what mechanisms symptoms are temporarily avoided (Shelley and Neligan, 1966). The suggestion that a high blood level of lactic acid may have a protective action, based upon convincing experiments in calves (Comline and Edwards, 1968), has not yet been confirmed in man. Alternatively it may be wiser still to prevent hypoglycaemia by early feeding with breast milk (Smallpeice and Davies, 1964) or by intravenous administration of glucose (Cornblath, Forbes, Pildes, Leubben, and Greengard, 1966).

AGGRAVATING FACTORS The concentration of glycogen in the liver is low in babies delivered before about 36 weeks because the late pregnancy rise has not yet occurred (Shelley and Neligan, 1966), and also in babies suffering from hyaline membrane disease because their store has been too rapidly consumed (Shelley, 1964). Such babies, as well as those suffering from exposure to a cold environment (Mann and Elliott, 1957), run an increased risk of hypoglycaemia, and appropriate steps should be taken.

\section{HYPOGLYCAEMIA OF INFANCY}

In the absence of any generally accepted agreement about definitions and subdivisions, the incidence of this type of hypoglycaemia cannot be defined, although it is clearly rarer than the neonatal form (Cornblath and Schwartz, 1966); one category, the idiopathic (see below), has been described as 'uncommon but not rare, occurring more frequently than diabetes mellitus in children under school age' (Marks and Rose, 1965). General recognition of the condition followed the description of 25 cases by McQuarrie (1954) and his dramatic statement that ACTH therapy 'appears to be as efficacious in infantile idiopathic hypoglycemosis as insulin in diabetes mellitus' (McQuarrie, 1955). Unfortunately this conveyed a false implication of a rational replacement therapy, and tended to obscure the need to seek a cause, or at least a mechanism, in every case; moreover experience has not confirmed the general efficacy of the treatment, although it may be a most useful empirical adjuvant in some cases.

Of the possible causes which have been described, pancreatic islet cell hyperplasia is doubtful in view of the technical difficulty of interpreting the histo- logical appearances (Marks and Rose, 1965), and an inability to increase adrenalin output in response to induced hypoglycaemia (Broberger and Zetterström, 1961) is as difficult to interpret in those cases as it is in the newborn. The latter finding may, however, explain why children suffering from convulsions, confusion, blank spells or coma due to this cause often fail to show the classical signs of hyperadrenalinism which usually accompany acute hypoglycaemia. This diagnosis must therefore always be considered in such children, and particular attention be paid to the timing of the symptoms with respect to fasting, meals, or minor infective illnesses. Another suggestive finding, even at this age, is a low birth weight relative to gestational age (Broberger and Zetterström, 1961), and the possibility of a familial incidence should be borne in mind.

An example of the diagnostic breakdown of 100 consecutive cases of hypoglycaemia in childhood is given by Cornblath and Schwartz. (1966, p. 194) and their schematic representation of the age at onset of different types appears in Fig. 3; but for the present purpose it seems best to divide the cases into three main categories.

CATEGORY A: IDIOPATHIC HYPOGLYCAEMIA OF INFANCY The name is a confession of failure to understand the cause. The peak age incidence falls in the latter part of the first year, and the symptoms usually occur following an overnight fast or during a minor febrile illness. The diagnosis can usually be confirmed by an overnight fasting blood glucose level of less than $40 \mathrm{mg} / 100 \mathrm{ml}$; if not, by an overswing to this level two or three hours after an intravenous test dose of glucagon, $0.03 \mathrm{mg} / \mathrm{kg}$, provided that the fall follows an initial rise of over $25 \mathrm{mg} / 100 \mathrm{ml}$ which excludes any defect of glycogen synthesis or breakdown. This overswing, which is commonly found in patients with an islet cell tumour, is not diagnostic of that condition. If appropriate tests do not place the case in either of the two categories which are described below, the 'idiopathic' label is applied and management consists of an empirical combination of measures to which the reaction of the individual case cannot be predicted, but has to be carefully observed (Haworth and Coodin, 1960). ACTH may produce a satisfactory response in acceptable doses, and can sometimes be stopped after a matter of weeks or months without a relapse. Dietary treatment may be either by low carbohydrate and high protein, or by adding small extra amounts of carbohydrate to a normal diet; either or both may succeed or fail in the individual case. More recent measures, as yet of uncertain value, include diazoxide, human growth hormone, and long-acting preparations of glucagon 


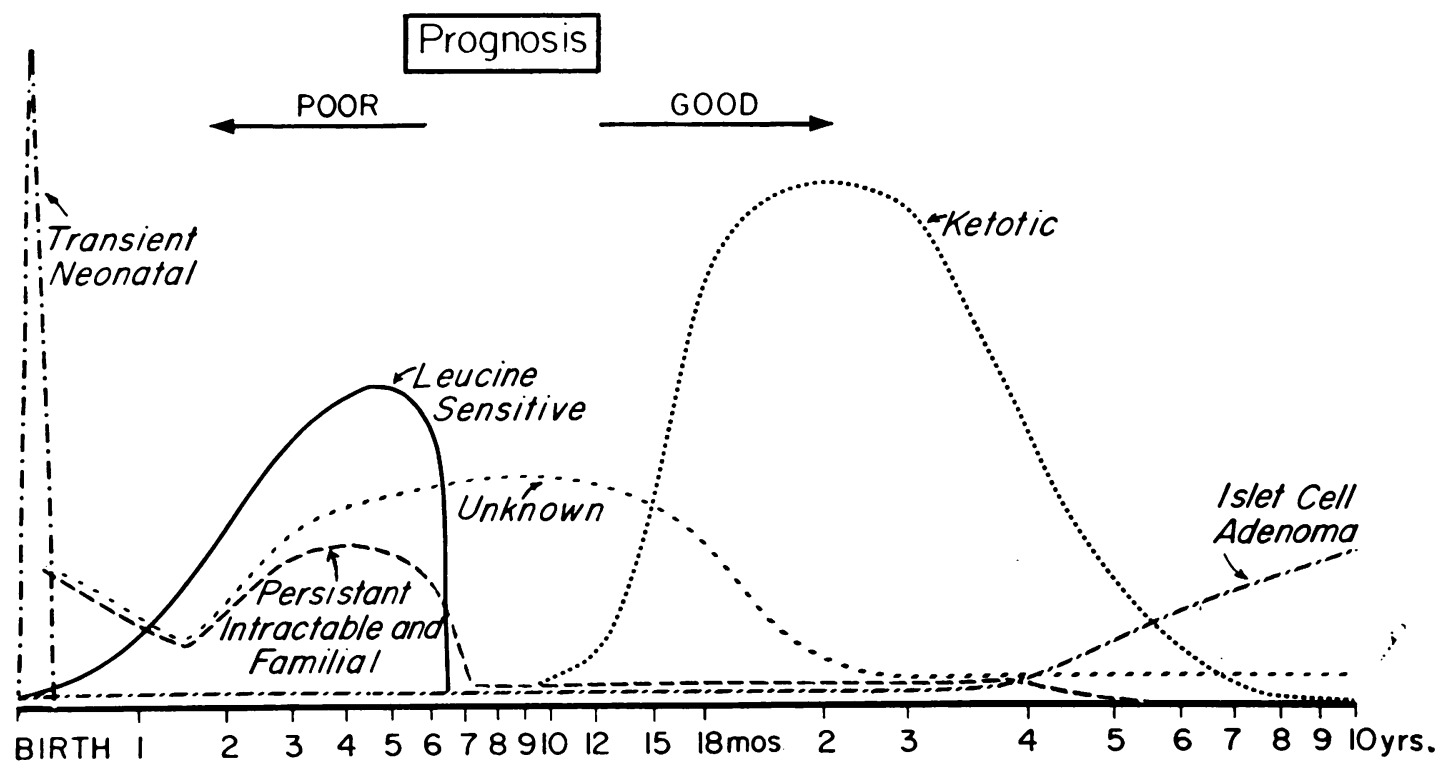

FIG. 3. Schematic representation of the age distribution of the various types of idiopathic hypoglycaemia. No true incidence data are available and the maxima are gross approximations. It should be noted that the age scale has been artificially manipulated for graphic presentation. The prognosis for transient neonatal hypoglycaemia is unknown; however, the persistent types with onset before the age of 6 months incur a poor prognosis. (After Fig. 52, by Cornblath and Schwartz, 1966.)

(Cornblath and Schwartz, 1966, p. 209). If all else fails, and in a heroic attempt to avert brain damage due to uncontrolled hypoglycaemia, subtotal pancreatectomy may provide at least temporary relief. In spite of everything, 21 of the 58 idiopathic cases reviewed by Haworth and Coodin (1960) showed evidence of 'mental retardation of varying degree'.

CATEGORY B: LEUCINE-SENSITIVE HYPOGLYCAEMIA The mechanism involved was discovered by Cochrane et al (1956), who described four cases, three of them familial, similar to the above except in that their symptoms never followed an overnight fast. The diagnostic test is to demonstrate significant hypoglycaemia within half an hour of an oral dose of casein, $1.5 \mathrm{~g} / \mathrm{kg}$, or L-leucine, $150 \mathrm{mg} / \mathrm{kg}$. The peak age incidence is within the first six months of life. The rational management, by a low leucine diet with added carbohydrate (see Cornblath and Schwartz, 1966, p. 277), is usually successful but may have to be continued for many years, or indefinitely.

CATEGORY C: KETOTIC HYPOGLYCAEMIA The definition of this condition, which is not as widely recognized or looked for as it probably should be, was placed on a sound basis by Colle and Ulstrom (1964). They reported eight cases in detail, and mentioned another 12 , in which the diagnosis was established by feeding a ketogenic diet for about $\mathbf{4 8}$ hours and so provoking first ketonuria, then hypoglycaemia with symptoms which could be promptly cured with intravenous glucose. In spontaneous attacks, which tended to occur after an overnight fast or during an infective illness in children over the age of 18 months, ketonuria always preceded the hypoglycaemia by some hours. They reported almost uniform success with a regime based on a carbohydrate-supplemented diet, reinforced with further carbohydrate whenever the parents detected ketonuria. If indicated, supplementary treatment with ACTH was usually effective. There was little or no evidence of permanent neurological damage.

\section{SUMMARY}

Hypoglycaemia is relatively frequent in childhood, particularly during the neonatal period, at an age when the brain is still in the stage of new cell formation and so particularly vulnerable to permanent damage. Babies of diabetic mothers and those who show signs of intrauterine malnutrition are particularly at risk during the neonatal period, and the latter are still at risk during later infancy, when other factors such as leucine sensitivity, or the effects of 
ketonaemia, may also begin to play a part. Immediate treatment is best given in the form of intravenous glucose; long-term treatment, if indicated, may involve modification of the diet, administration of $\mathrm{ACTH}$, and pancreatectomy as a last resort.

\section{REFERENCES}

Anderson, J. M., Milner, R. D. G., and Strich, S. J. (1967). J. Neurol. Neurosurg. Psychiat., 30, 295.

Broberger, O., and Zetterström, R. (1961). J. Pediat., 59, 215.

Cochrane, W. A., Payne, W. W., Simpkiss, M. J., and Woolf, L. I. (1956). J. clin. Invest., 35, 411.

Colle, E., and Ulstrom, R. A. (1964). J. Pediat., 64, 632.

Comline, R. S., and Edwards, A. V. (1968). J. Physiol. (Lond.), 198, 383.

Cornblath, M., Forbes, A. E., Pildes, R. S., Leubben, G., and Greengard, J. (1966). Pediatrics, 38, 547.

-, and Schwartz, R. (1966). Disorders of Carbohydrate Metabolism in infancy. Saunders, Philadelphia and London.

- Wybregt, S. H., and Baens, G. S. (1963). Pediatrics, 32, 1007. Cox, M., and Dunn, H. G. (1967). Develop. Med. Child Neurol., 9, 430.

Creery, R. D. G. (1963). Lancet, 1, 1423.

Dawkins, M. J. R. (1964). Proc. roy. Soc. Med., 57, 1063.
Farquhar, J. W. (1965). In Recent Advances in Paediatrics, 3rd ed., edited by D. Gairdner, p. 121. Churchill, London.

Haworth, J. C., and Coodin, F. J. (1960). Pediatrics, 25, 748.

—, Dilling, L., and Younoszai, M. K. (1967). Lancet, 2, 901.

Ingram, T. T. S., Stark, G. D., and Blackburn, I. (1967). Brain, 90, 851. Isles, T. E., Dickson, M., and Farquhar, J. W. (1968). Pediat. Res. 2, 198.

Lloyd, J. K. (1964). Proc. roy. Soc. Med., 57, 1061.

McCann, M. L., Adam, P. J., Likly, B. F., and Schwartz, R. (1966). New Engl. J. Med., 275, 8.

McQuarrie, I. (1954). Amer. J. Dis. Child., 87, 399.

- (1955). Ibid., 90, 591.

Mann, T. P., and Elliott, R. I. K. (1957). Lancet, 1, 229.

Marks, V., and Rose, F. C. (1965). Hypoglycaemia, Blackwell, Oxford.

Neligan, G. A. (1964). In Nutricia. Symposium on the Adaptation of the Newborn Infant to Extra-Uterine Life, edited by J. H. P. Jonxis, H. K. A. Visser, and J. A. Troelstra, p. 42. Stenfert Kroese, Leyden.

- (1965). In Recent Advances in Paediatrics, 3rd ed., edited by D. Gairdner, p. 110. Churchill, London.

, Robson, E., and Watson, J. (1963). Lancet, 1, 1282

Rabor, I. F., Oh, W., Wu, P. Y. K., Metcoff, J., Vaughn, M. A., and Gabler, M. (1968). Pediatrics, 42, 261.

Schiff, D., and Lowy, C. (1968). Lancet, 1, 475.

Shelley, H. J. (1964). Brit. med. J., 1, 273.

_, and Neligan, G. A. (1966). Brit. med. Bull., 22, 34.

Smallpeice, V., and Davies, P. A. (1964). Lancet, 2, 1349.

Stern, L., Sourkes, T. L., and Raiha, N. (1967). Biol. Neonat. (Basel), $11,129$.

Winick, M. (1968). Pediat. Res., 2, 352. 